\title{
Examination of Social self-efficacy levels of Female managers in textile industry by certain variables
}

\section{Songul TAMAM}

Institute Business Management and Law, Russia

\section{(C) The Author(s) 2018} \begin{abstract}
This research examined social self-efficacy levels of female managers in textile industry by certain variables. The General Self-Efficacy Scale and the personal information form prepared by the researcher for the purpose of the research were used to collect data. For the analysis of the data, t-test, F test and multiple comparison (Turkey's) tests were utilized. It was concluded that the social self-efficacy levels of the female managers who had been working for 11 years and longer were higher than those who had been working for $0-5$ years and 6-10 years. Another result of the research showed that the female managers who can speak a foreign language had higher social self-efficacy levels than those who cannot. The results were discussed in the light of the literature.
\end{abstract}

\section{ARTICLE HISTORY}

Received: 27/03/2018

Accepted: 07/07/2018

Published online: 05/10/2018

\section{KEYWORDS}

Efficacy, female manager, textile industry, social self-efficacy 


\section{Introduction}

Organizations manufacture goods and services for their customers, and when doing so, their main purpose is to keep customer satisfaction at the highest level possible. While achieving the customer satisfaction through quality, managerial competencies support a quality service (Agut, Grau and Perio 2003). Satisfying the customers depends on the competencies required by the job and possessed by the employees. Therefore, organizations look for competent employees that can adapt to changing market conditions and comply not with a given position but with the whole organization and organizational values. In addition, the main factor in the success of investments are considered managerial qualities and competencies (Jeou-Shyan, Hsuanc, Chih-Hsingd, Linb and ChangYen 2011). As information- and skill-based traditional management has fallen insufficient, wide managerial competencies have been defined recently. Competencies include knowledge, skills, abilities, attitudes and attributes desired or required in an individual (Suh, West and Shin 2012). On the other hand, Friedman and Kass (2002) defined self-efficacy as individual's perception of fulfilling the corporate tasks and ability to be a part of organization's social and political processes. Brownell (2008) emphasized that competencies are skills (learned behaviors) or qualities/abilities (personal attributes) required for being effective in the job. In another definition, it is stated that competencies include success-associated skills, knowledge, personal attributes and motivations (Gangani, McLean and Braden 2006).

Since self-efficacy affects preferences, therefore choice of profession and whether performing tasks required by the profession successfully, individuals with high general self-efficacy levels are expected to have higher probability of choosing difficult tasks which would improve themselves than those with low selfefficacy levels.Social self-efficacy helps individuals evaluate themselves to be successful in social relations (Bandura, 1977) and enable them to perform their abilities of social assertiveness high performance in general relationships, participation in a group or activity, friendly attitude and giving and receiving help. Similarly, Corcoran and Mallinckrodt (2000) state that individuals who have high levels of social self-efficacy are more skillful in solving the conflicts with others.

Research on social self-efficacy has shown that social self-efficacy level is related to self-esteem (Blake and Rust, 2000), depression (Jenkins, Goodness and Buhrmester, 2002), academic achievement (Bandura, Barbaranelli, Caprara and Pastorelli, 2001), problem-solving skills (Corcoran and Mallinckrodt, 2000), and stress and stress-coping skills (Matsushima and Shiomi, 2003). It is observed in the studies that efficacy is an important predictor of burnout and employees with lower self-efficacy levels quit their jobs more often (Evers, Bouwers and Tomic, 2002; Friedman, 2003). 
In today's environment where organizations and setting up an organization have gained importance, it is a common understanding how an organization maintains its existence and increase its competitiveness is about human resources rather than material resources. For scaling up in the competition, good management is of importance as well as other components in the textile industry. However, it is thought that having the human resource in the desired quality and amount is not sufficient alone for keeping up with the changes and moving with the times. Proper management and guidance of an organization's human resource becomes even more important, and such requirement is regarded mostly as the determinant of competition in labor-intensive industries such as textile (Masry, Katara and Demerdash, 2004). Hence, even if employees who have come together for common objectives and goals in businesses are experts in their fields, it will be difficult for them to achieve the required objectives and goals in the desired way without a competent manager who will guide them. In other words, the need will be always felt for a competent manager who can make and execute necessary decisions at the right time and rally others and establish the authority.

\section{Methodology \\ Research Model}

This research examined the social self-efficacy levels of the female textile managers. The relational survey model was used in the research. Relational survey models aim to identify the covariance among two or more variables and/or the degree of this covariance (Crano \& Brewer, 2002).

\section{Population and Sample}

The population was the female managers in the textile industry in Bursa province. The scales were applied to 208 female managers chosen with the random sampling method.

\section{Data Collection Instruments}

1-Personal Information Form: Aiming to collect information on the characteristics of the participant female managers, Personal Information Form comprises of questions about independent variables which are the subjects of examination in the research on the basis of resource review and expert opinions. The form was developed by the researchers in accordance with the purpose of the research and the independent variables as the subject of examination. 


\section{General Self-Efficacy Scale (GSE)}

The General Self-Efficacy Scale was first developed by Jerusalem and Schwarzer (1981) with 20 items, and the 10-item form was created later (Jerusalem and Schwarzer, 1992). Items of this 10-item Likert-type scale are graded between 1 and 4 in the original form. The lowest score that can obtained in the scale is 10 and the highest one is 40 . Higher scores mean higher levels of general self-efficacy.

Validity and reliability studies of the original scale have been carried out in different cultures and with different sample groups. First, Schwarzer and Schroder (1997) conducted validity and reliability studies in three different cultures, and the Cronbach's Alpha reliability coefficients were calculated to be $.84, .81$ and .91 . In another study performed in Germany, scale's test-retest reliability was calculated to be $r=.67$ (Schwarzer and Schroder, 1997). Test-retest reliability calculated with 2846 students was found $\mathrm{r}=.55$ in another study (Schwarzer and Scholz, 2000).

In a study carried out with 17,553 individuals from 23 countries about the universal structure of GSE (Schwarzer and Scholz, 2000), it was found in the basic components analysis that the scale had one subscale, the eigenvalues were 4.43 , the factor loads varied between .54 and .75 , and the internal consistency coefficients varied between .76 and .90 . Rimm and Jerusalem (1999) reported in validity and reliability studies for scale's Estonian form that the scale had one subscale (eigenvalue: 4.7 ), this explained $46 \%$ of the variance, the factor loads varied between .60 and .71 , and the internal consistency coefficient was .87 .

The first Turkish validity and reliability study for GSE was conducted by Erci (2005) with 130 adults who consulted a community clinic. Scale's test-retest reliability was found $\mathrm{r}=.83$ while its internal consistency coefficient was calculated to be $\alpha=.89$ in that study. It was also reported that scale's item-test correlation coefficients varied between 0.64 and 0.78 and the range of its factor loads were .64 and .79 .

\section{Data Analysis}

Independent groups t-test, which is a descriptive analysis technique, was used for identifying social self-efficacy levels of the female managers in textile industry, $\mathrm{F}$ test for determining female managers' demographics and difference of social self-efficacy, and Tukey's test for determining which groups created the difference. Significance level of the research was accepted to be .05 . 


\section{Findings}

Table 1. Results of t-test regarding whether there was a difference between social self-efficacy levels of the female managers by marital status

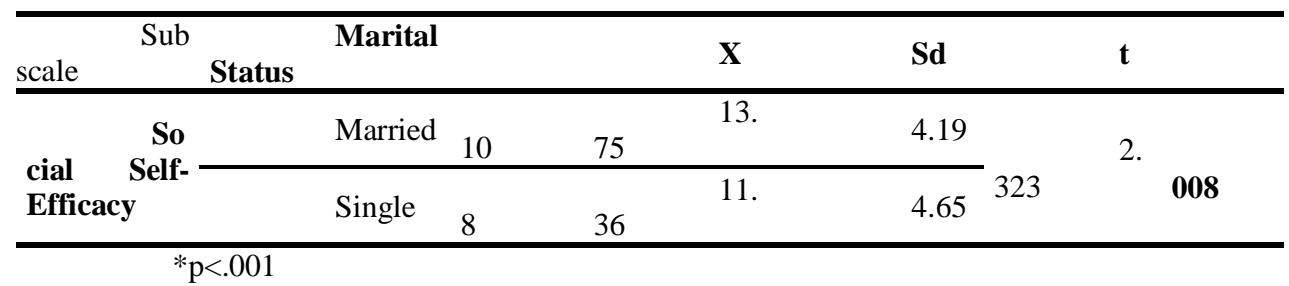

According to the social self-efficacy scores of the female managers by marital status, the married managers' arithmetic mean of social self-efficacy level was found $(X=13.75)$ while the single managers' arithmetic mean was found ( $X$ $=11.36)$. A significant difference $(t=2.323, p>.001)$ was found between the means.

Table 2. Results of t-test regarding whether there was a difference in social self-efficacy levels of the female managers by whether they can speak a foreign language.

\begin{tabular}{|c|c|c|c|c|c|c|c|c|c|c|c|c|}
\hline & $\begin{array}{l}\text { orei } \\
\text { Lan }\end{array}$ & $\mathbf{F}$ & & $\mathbf{N}$ & & $\mathbf{X}$ & $d$ & $\mathbf{S}$ & & $\mathbf{t}$ & & $\mathbf{P}$ \\
\hline $\bar{S}$ & & $\mathrm{~N}$ & & 7 & & 1 & & 4 & & & & \\
\hline $\begin{array}{l}\text { ocial } \\
\text { Self- }\end{array}$ & o & Y & 9 & 1 & & 1 & & 5 & 3.640 & - & $001 *$ & . \\
\hline Efficacy & es & & 29 & & 0.37 & & .98 & & & & & \\
\hline
\end{tabular}

As for female managers' social self-efficacy scores by whether they can speak a foreign language, arithmetic mean of the managers who cannot speak a foreign language was found $(X=13.07)$ whereas arithmetic mean of the managers who can was calculated to be $(\mathrm{X}=10.37)$. A significant difference could not be found between the means at $(t=-3.640, p>.005)$. It was concluded that the female managers who can speak a foreign language had higher social self-efficacy levels than those who cannot.

Table 3. Results of $F$ Test concerning whether there was a difference in the social self-efficacy levels of the female managers by their terms of employment

\begin{tabular}{|c|c|c|c|c|c|c|c|}
\hline Subsca & Term & & & d & & $\mathbf{F}$ & $\mathbf{P}$ \\
\hline $\begin{array}{l}\text { Social } \\
\end{array}$ & $0-5$ Years & & & & & 2. & .0 \\
\hline Self-Efficacy & & 9 & 3.38 & .477 & 345 & 05 & \\
\hline
\end{tabular}




\begin{tabular}{|c|c|c|c|}
\hline \multicolumn{4}{|c|}{ 6-10 Years } \\
\hline & 5 & 4.19 & .139 \\
\hline \multicolumn{4}{|c|}{11 years and } \\
\hline above & 8 & 5.21 & .367 \\
\hline
\end{tabular}

Significant differences was found in the social self-efficacy levels by terms of employment. A significance analysis was conducted to determine which groups caused the difference by female managers' terms of employment. Findings obtained from Tukey's test performed to see by which by which groups the difference is caused by managers' terms of employment are shown in Table 4.

Table 4. Results of Tukey's test regarding which groups caused the difference in the social self-efficacy levels of the female managers by terms of employment

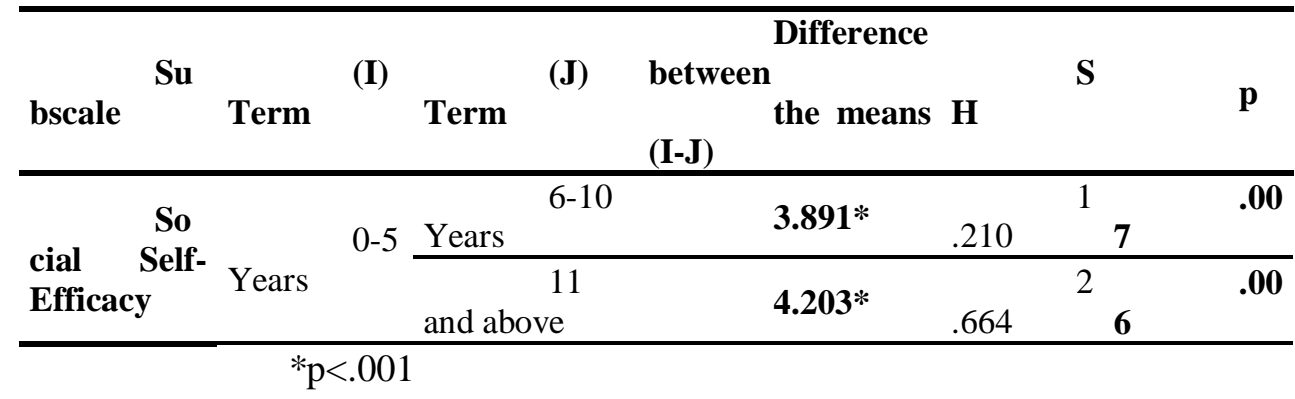

Given the social self-efficacy levels of the female managers by their terms of employment, the female managers who had been working for 11 years and longer were found to be have significantly higher social self-efficacy levels than those who had been working for 0-5 years and 6-10 years. Self-efficacy levels of the female managers who had longer terms of employment was found to be higher.

\section{Discussion and Conclusion}

The self-efficacy levels were found to be significant in favor of the single female managers in the research. A study in the telecommunication sector explored a relationship between competency and marital status (Wickramasinghe and Zoyza, 2008). This finding coincides with the findings of this research. It can be accordingly inferred that the married female managers who reel under several responsibilities such as children, husbands and house care laid by the social life could not exhibit their self-efficacy and skills sufficiently compared to the single female managers. Regarding the female managers' social self-efficacy levels by whether they can speak a foreign language, it was concluded that those who can speak a foreign language had higher social self-efficacy levels than those who cannot. About foreign language proficiencies, Andersson and Wictor (2001) state 
the fact that managers can speak a foreign language is highly effective in decision of organizations managers which are and want to be on the global level to enter the foreign markets. This result shows that global companies can start foreign transactions and highly tend to operate in foreign markets through the foreign language knowledge of their managers, and therefore, they have the leadership qualities.Foreign language is an important managerial quality for the managers of companies who want to globalize. Agut, Grau and Perio (2003) achieved a similar result.

Given the social self-efficacy levels of the female managers by their terms of employment significant differences were observed. The female managers who had been working for 11 years and longer were found to be have significantly higher social self-efficacy levels than those who had been working for $0-5$ years and 6-10 years. Self-efficacy levels of the female managers who had longer terms of employment was found to be higher.

Studies on that there can be general self-efficacy are based on the findings on the generalizability of self-efficacy in theory. Because, according to the Social Cognitive Theory, any performance completed successfully can be generalized to other fields that are associated with the field in question (Bandura, 1977). In other words, self-efficacy level that increased in a field due to successful performances can be transferred to other similar fields. Certain studies (Woodruff and Cashman, 1993; Rimm and Jerusalem,1999; Agarwal, Sambamurthy and Stair, 2000) showed that individuals develop a more generalizable or stable self-efficacy as a result of successful or unsuccessful experiences. Such generalized self-efficacy appears to be a personality trait later. This personality trait involves evaluations of the individual about his/her possible performance in the face of any new situation (Choi, 2004).

Stating that this decisiveness and continuity in self-efficacy, Eden and Kinnar (1991) explained that the reason is "general self-efficacy is a product of the life experiences and it has a structure which cannot be changed with short-term positive or negative experiences."

\section{Disclosure statement}

No potential conflict of interest was reported by the author.

\section{Contact Information}

E-mail: songul@gmail.com

Int. J. Hum. Soc. Dev. Res. 


\section{References and notes:}

Agarwal, R., Sambamurthy, V., \& Stair, R. M. (2000). Research report: The evolving relationship between general and specific computer self-efficacy-an empirical assessment. Information Systems Research, 11(4),pp. 418-430.

Agut, S., Grau, R. and Peiro, J. M. (2003). Competency Needs Among Managers from Spanish Hotels and Restaurants and their Training Demands, Hospitality Management, 22: pp.281-295.

Andersson, S. And Wictor, I. (2001). Innovative International Strategies in New

Firms-Born Globals the Swedish Case, 4th McGill Conference, September.

Blake, T. R. and Rust, J. O. (2000). Self-esteem and self-efficacy of college students with disabilities. College Student Journal, 36 (2), pp.214-226.

Brownell, J. (2008). Leading on Land and Sea: Competencies and Context, International Journal of Hospitality Management. 27:pp. 137-150.

Choi, N. (2004). Sex role group differences in specific, academic, and general self-efficacy. The Journal of Psychology, 138 (2), pp.149-159.

Corroran, K. O. and Mallinckrodt, B. (2000). Adult attachment, self-efficacy, perspective taking and conflict resolution. Journal of Counseling and Development, 78(4), p.473.

Crano, W. D. \& Brewer, M. B. (2002). Principles and methods of social research. New Jersey, Lawrence Erlbaum Associates Publishers.

Eden, D., \& Kinnar, J. (1991). Modeling Galatea: Boosting self-efficacy to increase volunteering. Journal of Applied Psychology, 76,pp. 770-780.

Erci B. (2005). Turkish version of General Self-Efficacy Scale, III. International - X. National Nursing Congress Book of Abstracts, İzmir.

Friedman I. A. \& Kass, E. (2002). Teacher self-efficacy: A classroomorganization conceptualization. Teaching and Teacher Education, 18(6),pp. 675-686.

Friedman, I.A. (2003). Self-efficacy and burnout in teaching. The importance of interpersonal-relations efficacy. Social Psychology of Education, 6 (3), pp.191-215.

Gangani, N., McLean, G. N. and Braden, R. R. (2006). A Competency-Based Human Resource Development Strategy, Performance Improvement Quarterly, 19 (1),pp. 127-139.

Jeou-Shyana, H., Hsuanc, H., Chih-Hsingd, L., Linb, L. ve Chang-Yen, T. (2011). Competency Analysis of Top Managers in the Taiwanese Hotel Industry, International Journal of Hospitality Management, 30: pp.1044-1054.

Masry S., Katara, H. and El Demerdash, J. (2004). A comparative study on leadership styles adopted by general managers: A case study in Egypt, Anatolia: An International Journal of Tourism and Hospitality Research, 15(2), pp.109-124.

Matsushima, R. and Shiomi, K. (2003). Social selfefficacy and interpersonal stress in adolescence. Social Behavior and Personality: An International Journal, 31,pp. 323-332.

Rimm, H, and Jerusalem, M. (1999). Adaptation validation of an Estonian version of the General Self-Efficacy Scale (Eses). Anxiety, Stress \& Coping, 12 (3), 329-345.

Suh, E., West, J. and Shin, J. (2012). Important Competency Requirements for Managers in the Hospitality Industry, Journal of Hospitality, Leisure, Sport \& Tourism Education, 11: pp.101-112.

Wickramasinghe, V., Zoyza, N. (2008). Gender, Age and Marital Status as Predictors of Managerial Competency Needs: Empirical Evidencefrom a Sri Lankan Telecommunication Service Provider, Gender in Management: An International Journal, 23(5):pp. 337-354.

Woodruff, S. L., \& Cashman, J. F. (1993). Task, domain, and general efficacy: A reexamination of the Self-Efficacy Scale. Psychological Reports, 72, pp.423-432. 